\title{
O poder político na energia e relações internacionais: o difícil equilíbrio entre o direito e a busca de segurança do Estado brasileiro
}

\author{
The power politics in the energy and international relations: \\ the hard balance between the law and search of brazilian \\ State security
}

JOSÉ ALEXANDRE ALTAHYDE HAGE*

Rev. Bras. Polít. Int. 51 (1): 169-186 [2008]

\section{Introdução}

A primeira década do século XXI está exigindo posicionamento bastante firme da política externa brasileira sobre dois problemas de larga envergadura. Trata-se dos problemas relacionados ao meio ambiente e aos esforços dos Estados nacionais para obtenção de combustíveis renováveis, da bioenergia, que toca à primeira vista o papel que Brasil pode ter neste desejado concerto por causa das graves complicações resultantes do aquecimento global, sobretudo. No fundo, são duas questôes interdependentes à medida que o equilíbrio ambiental está diretamente ligado à substituição, em parte, dos derivados de petróleo, óleo diesel e carvão mineral. Assim, há como dizer que o Brasil poderá ter lugar preeminente no em um possível concerto que venha a aliar esforços políticos com arranjos institucionais.

Mas não podemos afirmar, prontamente, que o Brasil esteja preparado para fazer frente às questóes mencionadas acima, nem às manifestações políticas que determinados Estados imprimem no já abalado sistema internacional. Sistema cortado por injunções de toda a ordem que acabam perturbando a busca de objetivo comum, a limitação do aquecimento global. O uso do poder político por algumas potências contribui para comprometer esforços de caráter universal. No campo da consecução energética há como ver que isto tem sido a regra nos últimos tempos, mormente na procura de garantir suprimentos energéticos.

Complicações surgidas há mais de dez anos relacionadas à crise do Estado em formular planos de investimento ainda perturbam o andamento brasileiro em

\footnotetext{
* Doutor em Ciência Política pela Universidade de Campinas - Unicamp e professor dos cursos de Relações Internacionais das Faculdades Trevisan e do Centro Universitário Ibero-Americano - Unibero (alexandrehage@ hotmail.com).
} 
busca de uma estratégia que sirva para seu desenvolvimento e para a transformação qualitativa internacional na energia, sendo uma das características dessa crise a falta de aparelhamento político apropriado à questão.

Se no cotidiano o sistema internacional é atravessado por conflitos de toda ordem, esta implicância tende a aumentar ainda mais quando se trata de assuntos energéticos. Isto porque os hidrocarbonetos, finitos à primeira vista, são elementos passíveis de disputas que podem migrar de simples embates diplomáticos em busca de mercados até guerras. Assim, os enfrentamentos podem ter outra feição em um futuro próximo, diferente das existentes anteriormente, muito mais dramáticas em virtude da exaustão dos carburantes e de sua concentração geográfica, embora haja possibilidades de no futuro haver novas explorações além das tradicionais, como as reservas ainda não confirmadas da Venezuela e do México, situação que também toca o Brasil, com as jazidas de Tupi.

Em um passado recente a grande característica dos conflitos internacionais pela disputa por petróleo era encontrada na existência de um grupo de grandes potências, e seus associados menores, procurando controlar de diversas formas as áreas geográficas tradicionais da produção petrolífera. Este desenho encontra seu melhor exemplo nos esforços do poder anglo-americano em disciplinar as contestações dos países petroleiros do Oriente Médio, sobretudo após a crise liderada pela Organização dos Produtores e Exportadores de Petróleo-Opep, em 1973, em as grandes potências passaram a formular modos de resistência, por exemplo, procurando aumentar a produção do Mar do Norte e do Alaska. ${ }^{1}$

Mas a feição tradicional exposta acima pode sofrer mudanças. Em acréscimo ao antigo conflito um novo ganhar corpo a partir da emergência de grandes Estados consumidores, que também são potências relevantes, em disputa com os antigos centros da política internacional. China e Índia transformam-se em novos pólos do poder mundial e são carentes de energia em virtude de suas economias altamente aquecidas na atualidade. Ambas as potências necessitam de instrumentos mais bem preparados para o bom relacionamento com o Oriente Médio; e essa manobra pode botá-los em rota de colisão com os Estados Unidos. Por isso a necessidade de se instituir novos padrões de desenvolvimento e energia para que o iminente conflito por reservas seja minimizado. Se a alternativa não ganhar vulto as novas potências consumidoras irão lançar mão dos carburantes poluentes, como o carvão mineral.

Padrôes de energia e de crescimento econômico que sejam convergentes com o equilíbrio ambiental bastante afetado pela poluição dos combustíveis fósseis são urgentes. Não restam dúvidas de que há grande necessidade de se pesquisar novos combustíveis alternativos, caso do biodiesel em que o Brasil pode ter papel de preeminência política e tecnológica. Sob tal aspecto, não poderá haver mais erros ou medidas tomadas incompletamente, visto que esses contratempos podem retroceder o pouco de avanço que pode haver.

1 Cf. SANTOS. "Petróleo - Quadro Estratégico Global no Início do Século XXI". p. 95 
Desta forma, tencionamos frisar que só há perspectiva de o Brasil contribuir firmemente para a resolução das questões ambientais e energéticas se o próprio Estado não negligenciar suas tarefas mais urgentes na confecção de uma estratégia coesa, pronta para responder às demandas interna e externa. Em outra dimensão, caberia à estratégia nacional não perder de vista os conflituosos cenários que emergem em virtude de más resoluções. A pouca atenção dedicada ao desgaste ecológico e a relativa displicência que as grandes potências expressam na questão energética são exemplos de resoluções feitas incompletamente.

Ainda que possa ser temporal é o conceito de estratégia de Golbery do Couto e Silva que preferimos utilizar, mas sem desconhecer que há outros. ${ }^{2}$ Por estratégia entendemos o planejamento do poder político, do Estado, para que faça levantamentos das condições políticas e econômicas tanto na esfera internacional quanto na doméstica e, daí, montar cenários que indiquem os caminhos que o país pode percorrer sem sofrer percalços e desgastes desnecessários. A estratégia deve ser inerente ao desenvolvimento ótimo do poder nacional, vale dizer a capacidade econômica do país, o avanço em ciência, tecnologia e estabilidade sócio-política, de acordo com quem muito estudou a conjugação, Oliveiros Ferreira.

Sobre a assertiva acima há dois comentários que pensamos ser pertinentes. Primeiro, o planejamento estratégico não significa a elevação de custos econômicos públicos na criação de estatais ou no emprego direto do Estado na esfera produtiva. O núcleo de planejamento estratégico pode ter sua existência na constituição plano em que haja coordenação sobre aquilo que foi escolhido como o objetivo nacional a ser alcançado em conjunto com a sociedade. Também somos consoantes com a ótica de Peter Evans e sua análise da industrialização brasileira, indiana e sulcoreana, seus avanços e impasses na concretização dos objetivos. ${ }^{3}$

Segundo ponto é que ao adotarmos o planejamento estratégico, o fortalecimento de autoridade pública não estamos, necessariamente, contribuindo para o enfraquecimento da democracia. Estados fortes tendem a resguardar poder nas áreas em que possa haver equilíbrio político e estabilidade econômica. É notório o papel do Reino Unido, ou do Japão, que consegue manter franquias democráticas sem ter de comprometer sua estratégia e os esforços para manter regular a busca de seus objetivos mais importantes, como o suprimento energético. ${ }^{4}$ Neste caso, o convivem bem a estratégia, a autoridade pública, com os direitos.

\section{A dificuldade do sistema internacional}

Resoluçōes feitas incompletamente têm efeitos mais nocivos para o âmbito da política internacional do que aquelas francamente hostis a confecções de

2 Cf. SILVA, Golbery do Couto e. p. 59.

3 Cf. EVANS. Autonomia e Parceria. p. 76.

4 Cf. OFFE. Problemas Estruturais do Estado Capitalista. p. 127. 
regimes específicos. Resoluções concebidas sob encomenda, para confundir uma possível opinião crítica global, só fazem conservar a situação distorcida sobre os temas que mais preocupam os Estados. Questão que deve fazer o Brasil ficar atento aos novos programas mal concebidos em que haja desigualdade de ânimo na aplicabilidade de regras acordadas por todos.

Como bem averiguou Guido Soares, árdua tem sido a tarefa de se compreender a abstração que há no relacionamento entre os Estados nacionais. ${ }^{5}$ Isto porque, de um lado, queremos um sistema altamente correspondido por regimes com legitimidade suficiente para fazer valer seu propósito. Em outro diapasão, desejamos que os poderes políticos possam ter força suficiente para sustentar suas vontades nacionais em assuntos que tocam, primeiramente, à população doméstica. Assim, o princípio do direito internacional, dos regimes e a política interna dos Estados entram em rota de colisão. Em parte isto é o que estamos percebendo com relação aos Estados Unidos no tocante ao meio ambiente e à energia.

E o imbróglio não se limitará às potências do hemisfério Norte, o impacto da industrialização chinesa, indiana e outros países também deverá provocar danos nos dois itens citados. A saber, danos no corpo de uma doutrina de direito e regimes internacionais e, por conseqüência, no equilíbrio ambiental, cujo descrédito político aumentará em virtude dos novos "peso-pesados" da economia internacional. Neste caso, o Brasil tem uma árdua tarefa a qual não pode se furtar, a de procurar instituir novas formas de convívio mais racional.

Isto porque contribuir para com a boa saúde do sistema internacional, no que vale para a economia e para a política, não significa abrir mão dos atributos nacionais. No mesmo passo, respeitar o destino de desenvolvimento e bem-estar nacionais não quer dizer "direito" que tem o Estado de fazer tudo o que seja possível por causa das incongruências da atividade política exterior.

A intenção deste trabalho se direciona justamente para procurar compreender as implicaçôes que ocorrem entre a busca de virtude da política internacional (liberal) na intenção de instituir regimes, bem como a emergência de posturas denominadas clássicas advindas dos Estados que tencionam manter interesse e conservar sua situação de grande potência, inclusive em assuntos que inicialmente não seriam congruentes com o poder político, como o comércio. Isto dá a entender, conforme pensa Jonathan Haslam, que o pensamento clássico, realista, tem sido constante, mesmo em concorrência as formulaçôes liberais, que perdem vigor rapidamente. $^{6}$

Na condição de potência regional esta não é uma análise estranha para um país das condições do Brasil. Dono de características próprias o Estado brasileiro não é uma grande potência, cujo impacto pode inibir e constranger a movimentação

5 Cf. SOARES. Curso de Direito Internacional Público. p. 112.

6 CF. HASLAM. A Necessidade é a Maior Virtude. p. 414. 
dos Estados mais fracos, inclusive localmente. Então, como prefere Celso Lafer, a posição do Brasil como potência média deve ser vislumbrada como meio de representar a demanda dos pequenos, advogando suas questôes, mas sem sofrer de introspecção ou timidez frente aos grandes do sistema internacional. ${ }^{7}$

Há muitos momentos em que pela falta de melhor precisão conceitual, ou exaltação de pensamento próprio, o analista acaba atribuindo ao termo sistema internacional o mesmo significado que ordem internacional, como se ambas fossem substantivas. Não há referências absolutas que negam o exercício dessa interpretação, entendendo um conceito pelo outro.

Contudo, preferimos assentar nossa opinião na idéia de que por ordem internacional compreendemos a maneira de como o mundo se apresenta desde a Paz de Westphalia, de 1648, cravejado de Estados nacionais soberanos. Vale dizer, soberanos à medida que as unidades políticas, como prefere Raymond Aron, guardam vontade nacional para resguardar sua liberdade e concepção de vida perante suas homônimas. E para resguardar liberdade de ação os Estados lançam mão de dois instrumentos interdependentes: a diplomacia e a guerra.

A ordem internacional é formada por Estados desiguais em riqueza, demografia, força econômica e outros fatores que agregam poder. Estados que são grandes potências e procuram não somente conservar a situação de preeminência, mas também ampliar seu poder junto às outras unidades, também tencionam fazer a mesma coisa: defender-se, ampliar seu poder de resistência ou de expansão. ${ }^{8}$ Neste aspecto, mesmo que seja redundante, só há ordem internacional porque há Estados nacionais que passam a conviver conservando suas diferenças.

Por isso, há como percebermos que pelo fato de o agrupamento dos Estados formarem uma ordem não significa, necessariamente, que o mundo seja democrático, equilibrado ou igual para todos. Ao contrário disso, o que tenta imperar é o sentido de anarquia, em que não haveria convenientemente, para muitos Estados, um ente superior que tencionasse constituir um governo mundial com regras, direitos e obrigaçôes prementes para todos os membros. Tal perspectiva de virtude teria de ser esperada pela montagem de um sistema internacional que tivesse amplas condições de amainar as disputas existentes no seio da ordem.

Por conseguinte, por sistema internacional, ainda com o autor de Guerra e Paz entre as Naçôes, compreendemos o modo pelo qual se apresenta a ordem internacional, dando-lhe forma e inteligibilidade política para tentar anular o sentido de anarquia que procura resistir. ${ }^{9}$ Usando a linguagem da informática podemos dizer que o sistema é a ferramenta que dá expressão ao computador, sua funcionalidade. Continuando com a imagem virtual dizemos que o sistema conforma a ordem, lutando em sua missão de dar legibilidade e ao mesmo tempo

7 Cf. LAFER. A Identidade Internacional e a Politica Externa Brasileira.p. 66.

8 Cf. EVANS et NEWNHAM. The Pinguin Dictionary of International Relations. p. 269

9 Cf. ARON. Paz e Guerra entre as Naçôes. p. 158. 
se adaptar aos avanços da tecnologia - fenômeno que empurra o sistema de informática para o desuso. Pensamos haver analogia entre o sistema internacional e o virtual.

O esgotamento de um sistema internacional não deixa vazio de poder, ele é instantaneamente substituído por outro que já estava em gestação, às vezes convivendo em paralelo com o antigo, esperando sua vez para ascender e ultrapassar os modos e estilos do anterior. Se nosso corte temporal é a partir de 1648, para não entrar em questôes importantes, mas impossíveis de serem contempladas em breve trabalho, concordaremos que a ordem internacional foi formatada por vários sistemas que corresponderam cada um à sua época. ${ }^{10}$

Para não alongarmos muito citamos que o sistema internacional vislumbrado após a Segunda Guerra Mundial foi o da pax americana, não plenamente consolidado em virtude de dois pontos: a coexistência com outra potência também possuidora de mensagem universal, a União Soviética até 1989, e falta de projeto em que os Estados Unidos possam contemplar os interesses dos países que aceitem a liderança da Casa Branca por algo mais compensador. Vale dizer, para se efetivar plenamente a pax americana, deveria haver um projeto de alcance universal em que aquela potência falasse e contemplasse os anseios da maior parte.

Da mesma forma que houve a pax britannica com sua mensagem liberal para aqueles Estados considerados afastados das conquistas da civilização ocidental, do livre-cambismo, do livre comércio, do individualismo possessivo, os Estados Unidos procuram reproduzir o mesmo ideário, mas, desta vez, com menos poder em seu teor de alcance universal em comparação a Londres. Eis uma das razões para haver forte embate entre concepções de civilização, em que o Oriente se recente de ser eclipsado em nome de certa racionalidade econômica. Afinal chegase à conclusão de que o estilo de vida americano não pode ser mundial. ${ }^{11}$

Após este arrazoado podemos dizer que se a dinâmica passa por uma dialética da disputa entre o desejo de se instituir um sistema internacional efetivo, com regimes, e a preeminência de se conservar uma ordem sem os freios para parar as locomoçôes das grandes potências, os assuntos ligados aos recursos energéticos e equilíbrio do meio ambiente, então, passam a ser temas cada vez mais integrados a essa disputa. Expliquemos. Em uma situação de conveniência política, ao menos para as grandes potências, a ordem internacional é cada vez mais proveitosa à medida que ela não seja barrada por medidas de virtude, de apegos ao direito.

Atualmente, não tem sido difícil observar que justamente as grandes potências, ou aquelas em via de sê-lo, estão em grande conflito para diminuir suas dependências dos combustíveis fósseis e, ao mesmo tempo, procuram modos para substituir os carburantes por intermédio de pesquisas. Em um mundo em que a ordem acaba legitimando os Estados a sobreviver como podem, vira uma árdua

10 Cf. FIORI. "Formação, Expansão e Limites do Poder Global". p. 53.

11 Cf. GRAY. O Falso Amanhecer. p. 163. 
tarefa a criação de regimes e regras internacionais em que tais disputas por bens, finitos ou não, seja sanadas e anuladas por um concerto legitimado por todos.

Neste caso, como escreve Stephen Krasner, não nos limitamos a pensar regimes apenas como pressupostos do direito internacional, ao observar que os regimes só são acatados porque são partes dos tratados internacionais. Mais do que isto, por regimes pensamos também um momento em que os Estados seguem determinada sugestão, ou norma, não porque está no tratado, mas porque lhes é importante e convergente com a concepção de que os Estados têm do interesses nacionais. 12 De fato a valoração dos regimes seriam importantes para temas que necessitam um mínimo de combinação de interesses, caso do petróleo.

Mesmo o professor de Harvard que compreende e milita pela expansão dos regimes internacionais é levado a reconhecer que no campo da energia, dos hidrocarbonetos especificamente, não tem sido fácil a concepção de arranjos institucionais por causa das implicações políticas que os carburantes causam na vida econômica e política de todos os Estados. ${ }^{13}$

$\mathrm{O}$ fato de os hidrocarbonetos serem finitos alimenta o grau de acidez da ordem internacional que, sem um sistema efetivo de controle, permite que os Estados aumentem suas disputas, sua corrida pela sobrevivência, como corpos naturais que passam por momentos de fortaleza e ocaso. Poucos momentos do convívio internacional têm sido tão expressivos para medir a urgência de um compacto sistema coerente quanto os ligados aos energéticos.

A urgência de segurança energética força os Estados a tomarem medidas auto-centradas, unitárias, para diminuir o grau de danos nacionais que podem ser advindas por falta de combustíveis. E falta de segurança energética são justamente os insumos básicos necessários para dar atividade regular ao transporte, à economia e aos instrumentos do poder nacional.

Uma explicação se faz necessária para precisarmos o termo. Por poder nacional compreendemos, como faz Oliveiros Ferreira, a coordenação estatal em nível estratégico, dos instrumentos que elevam qualitativamente a inserção do Brasil no sistema internacional. Avanços em ciência e tecnologia, industrialização, estabilidade política, militar e outros contribuem para a fundamentação do poder nacional quando coordenado pela estratégia. ${ }^{14}$

Este ponto, sob dialogo com Hans Kelsen, nos leva a perguntar como centralizar os assuntos energéticos e de meio ambiente na mão de um governo mundial ou de um sistema mais racionalizado. Ou de outra forma, como conformar uma comunidade internacional de fato em que os insumos estratégicos, como o petróleo, não sejam frutos de grandes conflitos internacionais. ${ }^{15}$

12 Cf. KRASNER. "Structural Causes and Regimes: Regimes as Intervening Variables". p. 1 e 2.

13 Cf. Cf. KEOHANE. After Hegemony. p. 150.

14 Cf. FERREIRA. A Crise da Política Externa. p. 41.

15 Cf. KELSEN. Derecho y Paz en las Relaciones Internacionales. p. 85. 
Aqui há uma questão que necessita ser explicada. Da mesma forma que a ordem não é justa, nem democrática para todos os Estados nacionais, já que eles são bastante diferenciados em seus artifícios de poder, o sistema internacional também não necessita ser distinto. Quer dizer, o sistema internacional pode procurar fomentar algo novo e virtuoso para os Estados ou apenas manter as diferenças e disparidades logradas pela ordem tradicional.

A comunidade internacional sim é amplamente carregada de concepções e desejos de virtude e ética entre os Estados. Viver sob uma comunidade subentende compartilhar recursos importantes, bem como administrar situaçôes em que, na normalidade, acarretam guerras. No entanto, acreditamos que o mundo está sob um sistema limitado em suas ações mais evidentes, sobretudo em temas que tocam à segurança energética dos Estados, a aquisição de combustíveis fósseis, biomassa e a complicada e conflituosa posição da energia nuclear.

Este problema pode ser examinado na atual situação brasileira. País relativamente rico em hidrocarbonetos passa por auto-suficiência. A descoberta das relevantes jazidas de petróleo e gás natural da Bacia de Tupi, Santos, é um fato. Porém, o Brasil poderá volta a ser importador de petróleo pela exaustão de suas reservas, com prazo de 40 ou 50 anos de auto-suficiência, dependendo da maneira de como o País lidará com a riqueza, exportando-a em grande monta ou resguardando-a para melhor aproveitamento, bem como o ritmo de seu crescimento econômico.

Assim, acreditamos que o Brasil necessita de uma política energética que não somente seja preocupada com a questão nacional, mais do que isso, tenha uma sensibilidade em relação ao problema internacional da energia e do meio ambiente. Um prazo de 40 ou 50 anos de auto-suficiência parece ser confortante à primeira vista. ${ }^{16}$ Mas em um plano geral, de futuro para o Estado, o tempo citado talvez não seja tão largo assim, pois a permanência das reservas depende de um conjunto de fatores domésticos ou internacionais.

O México, com histórico mais importante na área de petróleo do que o Brasil, não pode mais se arrogar de ser um grande exportador, pois suas reservas estão minguando rapidamente. A Indonésia saiu de posição confortável de exportadora para possível importadora no médio prazo. Com efeito, um alerta a respeito das possibilidades brasileiras serve como prudência. ${ }^{17}$

Grandes são as oportunidades do Brasil de se tornar fornecedor em alto grau de petróleo e biocombustíveis para um sistema interestatal com vias de dificuldade operacional nas principais zonas de exploração, Oriente Médio e Ásia Central.

16 Trata-se de estimativa baseada na Teoria de Hubbert que indicava a auto-suficiência petrolífera do Brasil até 2017 ou 2020. Após a descoberta da Bacia de Tupi, em outubro de 2007, há cálculos que indicam ter dobrado as reservas nacionais. De acordo com tal ferramenta a auto-suficiência deverá chegar a 2030 . O conhecimento técnico sobre a Teoria de Hubbert pode ser encontrado nas aulas do professor Carlos Américo do IEE-Politécnica, Universidade de São Paulo, a quem recorremos para o assunto mencionado.

17 CF. HAGE. "Especialista diz que dependência do gás boliviano não acaba tão cedo". Em 30.11.2007. 
Complicações que advém por causa de conflitos políticos de alta intensidade, antes de tudo são marcantes. Se o petróleo tem o poder de provocar conflitos de toda ordem não há por que negligenciar o papel do álcool combustível nas implicações políticas, ainda que no longo prazo. ${ }^{18}$

Embora o Crescente do mundo islâmico, e adjacências, seja a principal área de prospecção petrolífera, com empresas estatais gigantes, como a Saudi Aramco, isto não significa que o comando político esteja nos Estados produtores. Após a crise de abastecimento mundial, em 1973, as grandes potências consumidoras dividiram ardilosamente a rede de exploração, transporte, refino e negociação do insumo; dando ao eixo Nova York - Londres o comando das operaçôes, inclusive preços. ${ }^{19} \mathrm{O}$ que vale para o petróleo poderá valer também para os combustíveis renováveis. A seguir, dedicaremos mais tempo para analisar a questão nacional.

\section{A situação brasileira}

À primeira vista podem aparecer dúvidas se nosso raciocínio a seguir guarda relação com o propósito deste trabalho, o de analisar a pertinência da política internacional com a projeção brasileira na consecução de segurança energética. Procuraremos mostrar que há correspondência entre a desarticulação do poder publico nacional com o direito e política internacionais, às quais o Brasil tenciona tomar parte como ator de grande importância na mudança qualitativa do sistema.

Também é pertinente dizer que quando tratamos de energia fazemos de modo amplo, não nos limitamos a um insumo, mas procuramos abarcar a "questão energética" em si, resultado do agrupamento da energia elétrica, do gás natural e do petróleo que pode comprometer a segurança energética do Brasil por falta de melhor coordenação política. Isto porque, no fundo, a falta de consecução em um dos insumos ou serviços é resultado da ausência de projeto político que deveria ter no ministério brasileiro das Minas e Energia um dos seus braços. ${ }^{20}$

E na escala da política internacional não há dúvidas de que uma melhor inserção por parte do Brasil será mais bem preparada à medida que o país tenha condiçôes de suportar os contratempos externos em virtude da disputa energética. Contudo, ainda que a energia elétrica seja um fator doméstico, gerada na maioria por usinas brasileiras, ela não escapa da lógica internacional, já que agências financeiras e agentes empresariais encaram a energia elétrica também como um bem negociável internacionalmente, pois são elementos passíveis de investimentos externos.

A década de 1990 fora de grande complexidade política para o Brasil. O país saiu de uma posição em que se procurava obter um núcleo munido de autoridade,

18 Cf. HAGE. "O Brasil na Economia Internacional”. p. A-14.

19 Cf. GOWAN. A roleta global. Pg. 83.

20 Cf. CARVALHO. "Construção e Desconstrução do Sistema Elétrico Brasileiro". p. 102. 
reconhecida em quase todos os parâmetros da sociedade, para um nível em que as denominadas forças do mercado alocassem as melhores situações para investimento em obras outrora consideradas estratégias. Estratégicas à medida que afetavam a consecução de segurança do Estado brasileiro.

Eis um complicador. Na época do desenvolvimento nacional incorporado pelos governos militares, o Estado havia constituído autoridade sobre o setor energético de forma geral. No campo hidroelétrico houve a presença do sistema Eletrobrás que gerava, transmitia e coordenava grande parte da eletricidade trabalhada pelas empresas congêneres estaduais. Aqui há como dizer que havia plano estratégico de longo prazo, embora as condições políticas e sociais fossem delicadas.

Delicadas pelo fato de que a autoridade exercida pelo poder público não apresentava canais de comunicação regulares com a sociedade civil, por exemplo, com o setor social que deveria ser desalojado de seus terrenos para que estes servissem na construção das hidrelétricas. Questão reconhecida pelo Banco Mundial, mas que serviu como justificativa para a desregulamentação do sistema, já que a essência do poder público é ser antidemocrático, como preferia argumentar aquela agência. ${ }^{21}$ Neste caso, há um arcabouço possuidor de autoridade e regulação que peca por falta de comunicação, como pode haver em governos autoritários.

Em outro diapasão, há governos que podem ser sensíveis a pressões setoriais, mas que não gozam de plano estratégico para segurança energética, como houve na situação do "apagão", em 2001. Crise que houve, inter alia, por desigual relação entre o Brasil e as organizaçóes financeiras internacionais. O ponto ótimo da relação, como tivemos oportunidade de escrever, seria a existência de um ente democrático com poder reconhecido por todos.

Por conseguinte, em nossa tese de doutorado tivemos oportunidade de melhor expor as questões político-econômicas por que passou o Brasil. ${ }^{22}$ Sob o desejo de atrair fluxos financeiros internacionais, que pudesse tirar o País do fraco cotidiano de atração financeira e de investimentos, o governo federal, com anuência de alguns estaduais, concordou em reformar os instrumentos de ação do poder publico. Um dos resultados daquela reforma foi a diminuição de coordenação da coordenação governamental sobre determinados serviços urgentes ao Estado, como energia.

$\mathrm{Na}$ visão de Roberto Grün a plataforma governamental do governo Fernando Henrique Cardoso fez trabalho corrente para preparar o terreno à reforma institucional. Procurou fazer alterações conceituais, mais do que políticas, para neutralizar intelectualmente os críticos, dando a entender que aqueles se opusessem ao programa de desregulamentação deveria ser partidários de privilégios ou de corporaçōes arraigadas em confortos públicos. Daí seria grande o apelo à sensibilidade da opinião público que se voltaria a tais posturas. ${ }^{23}$

21 Cf. BERNANN. Os Limites dos Aproveitamentos Energéticos para Fins Elétricos. p. 211.

22 Cf. HAGE. Bolivia, Brasil e a Guerra do Gás. p. 51.

23 GRÜN. "Reforma do Estado e "apagão" cognitivo. p. 890. 
Ficara patente que o Brasil havia acatado medidas controversas pelo fato de que o poder de investimento do governo federal entrara em fase decadente para os serviços públicos. O projeto de transformar o país em algo palatável para o investidor internacional contribuiu não para angariar crescimento estável e, ao mesmo tempo, conveniente para a estrutura de autoridade política do Estado, mas sim para cumprir um organograma estabelecido pelas agências internacionais de risco, conforme a leitura de Paulo Nogueira Batista Júnior. ${ }^{24}$

Com efeito, os mais importantes países sul-americanos, sobretudo o Brasil, entraram em um ritmo chamado Estado Normal, conforme a verificação de Amado Cervo - a franca desestruturação do país para coordenar as atividades econômicas e para planejar o desenvolvimento. ${ }^{25}$ A falta dos instrumentos essenciais do poder publico o Estado normal aceita a "estratégia" sugerida pelas organizações internacionais diretamente contrárias à coordenação econômica do Estado. $\mathrm{Na}$ ânsia de se superar crises econômicas e frisar prontamente $\mathrm{o}$ abandono do antigo projeto de substituição de importações Brasil, Argentina e outros preferiram o modelo que também seria integrante do programa de política externa dos mesmos países.

Cervo utiliza três paradigmas para enquadrar as manifestaçôes políticoeconômicas dos Estados sul-americanos no clima de transformação conceitual dos anos 90. Primeiro, o Estado Desenvolvimentista seria aquele que planejava diretamente no campo da economia, via empresas estatais e agências específicas para o desenvolvimento nacional, caso do Brasil no período do nacional-desenvolvimentismo. $\mathrm{O}$ segundo são os países que privatizaram todo o centro aglutinador de desenvolvimento, como a energia de modo geral, se enquadram na tipologia de Estado Normal, situação da Argentina durante o governo de Carlos Menem.

A posição mais conveniente do ponto de vista político seria a construção do Estado Logístico, em que o poder público é resguardado de infiltrações ou influência de toda ordem, segue:

O terceiro é o paradigma do Estado Logístico que fortalece o núcleo nacional, transferindo à sociedade responsabilidades empreendedoras e ajudando-as a operar no exterior, por modo a equilibrar os benefícios mediante um tipo de inserção madura no mundo globalizado.

Não há como imputarmos livremente qual paradigma se encaixa o Estado brasileiro, pois o país incursiona nos três, dependendo das condições políticas e fatores internacionais. Contudo, para o Brasil não bastava somente reformar os instrumentos de coordenação nacional importantes, como os encontrados na área da energia e da comunicação, em proveito dos grandes fluxos financeiros nacionais e internacionais. Haveria de ter também, na medida do possível, mudanças conceituais no antigo programa da política externa brasileira, para que ela fosse mais palatável

24 BATISTA JUNIOR. Os Mitos da Globalização. p. 42.

25 Cf. CERVO. "Um balanço da era Cardoso". 8. 
aos fenômenos que passaram a ser chamados globalizantes, como a abertura dos mercados nacionais, as privatizações e o baixo teor da atividade autônoma.

Obter reforma conceitual na diplomacia brasileira seria essencial para a emergência de uma burocracia competente, atualizada e sensível aos novos vetores da política internacional, não mais conformados pela "política do poder" como antigamente, mas sim por novos, por exemplo, respeito à propriedade intelectual e a outros temas que são caros às chancelarias dos países industrializados.

Inerente a esse ponto ficou claro que haveria também uma "globalização energética" que ficara represada pelas engessadas políticas tradicionais dos grandes Estados sul-americanos, até 1990. Mas após aquela data a situação mudaria porque a reforma conceitual da política externa, no caso brasileira, deveria trabalhar para projetar melhor imagem do país. Desta vez, o Brasil deveria ser apresentado como ente respeitador do investimento externo e lugar no qual o empreendedor particular, internacional ou não, seria contemplado por sua decisão.

Neste aspecto, a corrente intelectual mais cosmopolita, que advoga os avanços de um tipo de globalização, também viu com pertinência a desarticulação do poder público dos grandes Estados em desenvolvimento. De acordo com Mohamed Ayoob houve uma espécie de perigoso mimetismo por parte das elites político-econômicas dos países em questão, dando a entender que os modelos adotados pelo Brasil, e outros, já haviam sido testados positivamente nos países industrializados. Portanto, nada mais conveniente para os Estados periféricos utilizar modelos socioeconômicos tidos por racionais e modernos, o Reino Unido, por exemplo. Mas o problema de fundo foi reproduzir o modelo britânico, ou alemão, de liberalização, mas sem o acompanhamento de seu poder público que se faria necessário na regulação. ${ }^{26}$

Certamente, tal raciocínio não foi desprovido de prejuízos aos Estados mais pobres economicamente, visto que eles anuíram por um modelo político que contribuiu para apenas fazer migrar as açóes estatais, antes altamente mal avaliadas pelos agentes financeiros internacionais. Quer dizer, a atenção do Estado saiu da coordenação econômica, em grande parte, para resolver questôes agora ligadas à segurança publica e social em franca crise por causa da emergência de um jogo econômico nem sempre em consonância com a distribuição de bem-estar. Em muitas situaçóes o gasto estatal subiu por causa da violência urbana.

Já no campo da energia a reforma institucional marcou presença em duas linhas de atuação do poder público nacional, mas com velocidades e implicações não necessariamente iguais. Primeiro, no campo da energia elétrica houve a privatização de quase todo o sistema Eletrobrás que fora concebido, desde a década de 1960, como centro de aglutinação e coordenação dos subsistemas regionais e estaduais, interligados. A lógica do sistema Eletrobrás estava na possibilidade que ele adquirira para transferir e regular fluxos energéticos de lugares mais abastecidos

26 Cf. AYOOB. Inequality and Theorizing in International Relations. p. 28. 
energeticamente para outras localidades com problemas de fluxos regulares, com picos de alta e baixa de energia elétrica, caso do Sudeste industrializado. ${ }^{27}$

É necessário frisar que a privatização da antiga holding fora justificada em virtude de volumosas contabilidades negativas que o Estado havia adquirido desde os anos 80, com a ascensão dos custos da dívida externa que contribuiu para abortar o projeto nacional de desenvolvimento. ${ }^{28}$ Contudo, não se tornou verdadeira a tese de arrecadamento pelas privatizaçôes para aumentar o poder de investimento do Estado, agora mais "enxuto" por ter privatizado as antigas empresas do serviço público. Ao contrário, os déficits orçamentários do governo federal em toda a década de 1990 conservou-se alto pelo mau uso dos recursos.

E mais, em parte, a confiabilidade em um serviço elétrico que fosse palatável a um projeto nacional de desenvolvimento fora posto em xeque em nome de um modelo de administração pública, mais sensível às pressóes das agências financeiras e organizações internacionais, como o Banco Mundial. José Goldenberg e Luiz Tadeu Prado demonstram o quanto faltou plano de ação condizente com a situação crítica das geradoras de energia elétrica:

Todas essas dificuldades do setor elétrico foram induzindo, paulatinamente, a uma deterioração das reservas do sistema anteriores à reforma. Essa situação era agravada pelo fato de que as geradoras federais que pretendiam fazer novos investimentos para tornar o sistema menos vulnerável foram impedidas de fazê-lo pela política de austeridade fiscal do governo. ${ }^{29}$

Os escândalos sobre a empresa norte-americana de energia Enrol, em 2000, revelou o quão havia sido delicada a privatização das empresas estaduais hidrelétricas, coordenadas pelo sistema Eletrobrás. Isto porque uma das maiores empresas do antigo arranjo elétrico, a paulista Eletropaulo, havia sido adquirida justamente pela empresa em questão, envolvida em crise de confiabilidade por causa de "maquiagem" nas contas de auditoria feitas por consultorias dos Estados Unidos, um grave passo que conturbou o mercado de ações.

Para salvar a Eletropaulo da solvência, já que a cabeça da holding entrara em profunda crise de confiabilidade nos Estados Unidos, o erário brasileiro volta a investir na ex-estatal paulista por meio de repasses do Banco Nacional de Desenvolvimento Econômico e Social-BNDES. ${ }^{30}$ Instituição que em 1995 fora proibida de ajudar a própria Eletropaulo. Se assim não ocorresse a crise elétrica, mais a econômica em voga, seria violentíssima para a produção nacional, isto porque ela abarcaria a região mais industrializada do Brasil.

27 Cf. ROSA. O Apagão. p. 29. Neste caso, nos referimos, com Pingueli Rosa, a privatização das empresas estaduais de energia elétrica que, em conjunto, eram coordenadas pelo sistema Eletrobrás. Há empresas estaduais ainda estatais, caso das Companhias Elétricas do Paraná e de Minas Gerais.

28 Cf. FERREIRA. Opus cit. p. 35.

29 GOLDENBERG et PRADO. "Reforma e crise do setor elétrico no período FHC". p. 230.

30 Cf. SOLNIK. A guerra do apagão. p. 68. 
Já no segundo serviço de abastecimento energético, dos combustíveis e derivados de petróleo, a situação não foi tão profunda e vulnerável como fora a da energia hidroelétrica. No caso da desregulamentação do setor petroleiro houve a interpretação de que os governos reformadores dos anos 90 procuravam neutralizar oposições e críticas, partindo dos setores menos politizados para os mais complexos politicamente. Mas no final das contas, o objetivo final seria fechar o cerco em todos os níveis de empreendimento publico, até na esfera do petróleo.

Em todo o caso, ainda que as plataformas reformistas do poder público não tivessem ampla mobilização política para concluir o programa da reforma institucional do Estado brasileiro, solvendo o poder político, conseqüências foram criadas com poder de alterar o quadro energético nacional no que tange à produção e serviço de petróleo no Brasil. Sérgio Ferolla e Paulo Metri apontam as conseqüências econômicas e políticas que o Congresso nacional fizera, ao quebrar o monopólio nacional do petróleo, permitindo a exploração de outras empresas:

Da mesma maneira, o governo federal, no período de 1995 a 1997, comprometido com a aplicação das teses neoliberais de interesse do poder econômico internacional, explicitadas pelo FMI e pelo Banco Mundial, e utilizando toda sua força política, interveio no setor de petróleo conseguindo aprovar a Emenda Constitucional número 9, de 9 de novembro de 1995, que buscava acabar, de modo camuflado, com o monopólio estatal do petróleo, bem como a Lei número 9.478, de 6 de agosto de 1997, que, sem subterfúgios de e de forma clara, terminou com o monopólio e deu origem à ANP. ${ }^{31}$

Assim, fica patente que o Brasil não teria condições de participar dos negócios internacionais em pé de igualdade com os Estados que, apesar dos contratempos, haviam conseguido manter controle sobre áreas consideradas estratégicas para a segurança nacional, como a energia. Sem o incremento político necessário para dar voz no meio do sistema internacional o Brasil ficaria desprovido de instrumentos importantes também para se fazer respeitar o direito internacional.

Neste particular, concordamos com Hedley Bull para quem o acato ao direito internacional não se faz pela formalidade ou rigidez da letra registrada, mas sim por meio de açóes políticas que aumentem a legitimidade do próprio direito. ${ }^{32}$ Quer dizer, o Brasil para valorizar o direito deve ter instrumentos políticos essenciais para fazer valer sua defesa do próprio direito e não deixar que esta prerrogativa de primeira ordem seja advogada por terceiros atores.

Ampliar o escopo do direito internacional, para o autor de $A$ sociedade anárquica, é fazer com que cada Estado assuma sua responsabilidade, seu naco

31 FEROLLA et METRI. Nem Todo o Petróleo é Nosso. p. 193. ANP significa Agência Nacional do Petróleo, como meio de a sociedade obter controle sobre os serviços privatizados, neste caso o comercio de derivados de petróleo. Para os autores mencionados a agência em questão não foi aparelhada politicamente para lograr tal tarefa. Ao contrário disso, a ANP foi constituída para se enquadrar ao critério dos interesses das empresas concorrentes da estatal brasileira.

32 Cf. BULL. A sociedade anárquica. p. 240. 
de ações, perante seus homônimos. Mas a assertiva é importantíssima para tal fim. Para se fazer inserção internacional em que o Estado imprima sua visão e, ao mesmo tempo, acate a ordenação universal é necessário, antes de tudo, que haja efetivamente Estado, a saber, poder publico sabedor de seu papel. Eis uma verdade que pode ser válida para o Brasil em sua inserção internacional.

Não há dúvidas de que o assunto energia deixou de ser algo apenas ligado à esfera interna dos Estados, mesmo aqueles que são donos de reservas respeitáveis em variados insumos. Aqui, algumas assertivas são por demais evidentes. Se o Estado é grande consumidor de energia importada, hidrocarbonetos, por exemplo, ele deverá reforçar em moldes eficientes seu poder nacional, bem como seus artifícios de poder integrados à política externa.

Em outra instância, se for o caso de um Estado exportador, como os da Opep, ele deverá se esforçar longamente para valorizar o máximo seu produto, sem a qual não há elevação da riqueza nacional. Esse embate pode ser visto na atualidade do Oriente Médio em que alguns exportadores tencionam resguardar sua produção para alcançar alto valor, caso da Arábia Saudita.

\section{Considerações finais}

No século XX e no atual os conflitos e disputas por posses de estoques energéticos têm sido constante. Os embates existentes há tempos no Oriente Médio e Ásia Central são uma amostra disso. As grandes potências industrializadas, com crônica pobreza em hidrocarbonetos, direcionam seus poderes para áreas em que ainda pode haver grandes estoques de petróleo, sendo essas áreas encontradas na franja da ex-União Soviética e na África Ocidental.

Se os andamentos político-energéticos continuarem na situação da atualidade tudo indica que o sistema internacional, já abalado pela difícil construção de um regime apropriado, passará por profunda crise. E essa crise será de nova conformação pela emergência de novos atores em disputa com os antigos pela preeminência nas áreas ainda promissoras para exploração. Por vias indiretas há a impressão de que a região petrolífera, estendida do Oriente Médio a caminho da Ásia Central, será mesmo o heartland a qual tempo dedicou o geopolítico britânico Mackinder, área rica em insumos estratégicos que deverá ser disputada pelas antigas potências e as mais recentes: Reino Unido, Rússia, Estados Unidos e China. ${ }^{33}$

Por ser a configuração do sistema internacional feita sob o impacto da disputa e dos conflitos os Estados nacionais procuram resguardar seus elementos essenciais do poder nacional, como influência política e segurança energética. O período em que se elevou programaticamente a reforma institucional não foi uniforme para todos os países. As potências industrializadas não adotaram as medidas reformistas, não da forma como se imaginou nos países em desenvolvimento.

33 Cf. HAVERY. O Novo Imperialismo. São Paulo, Loyola, 2004. p. 42. 
Por outro lado, os mesmos paises que ainda se ressentem pela falta de instrumentos políticos eficazes, para dar cabo de problemas sociais volumosos, filiaram-se a um modelo político e econômico que, no fundo, nem os grandes centros da política internacional valorizaram. De outro modo, os Estados em desenvolvimento fizeram alterações em sua conformação de poder nacional que foram além do concebido por serem agrupamentos de nações pobres; enquanto que as desenvolvidas conservaram muito de sua influencia e poder.

No campo da energia, hidrelétrica e carborifica, os exemplos podem ser encontrados sem dificuldade. Vejamos o que ocorreu no México e na Indonésia entre 1995 e 1999: solvência elevada de seus poderes para que os dois países fossem convidativos ao grande investimento externo. Mas quando México-DF e Jacarta deram sinais de esgotamentos todas as agências de avaliação e internacionais deram-lhes negativas. Assim, a crise econômico-política desses países cresceu em níveis insuportáveis, castigando as classes sociais mais pobres.

Tal advertência tem de ser percebida pelo Brasil e outros Estados de condiçôes políticas e econômicas análogas. Como o professor Afonso Arinos de Mello Franco falava: "para que a nação faça inserção internacional de qualidade é necessário que haja nação, quer dizer, que haja Estado, vontade nacional para participar com respeito e amor-próprio" (sic).34 E Afonso Arinos entendia muito do que estava falando, afinal fora o grande professor de direito internacional de muitos.

$\mathrm{O}$ ano de 2007 tem posto o Brasil em evidência quando se trata de assuntos energéticos, sobretudo aos elementos do álcool combustível e do biodiesel. Além da competência nacional nos combustíveis sintéticos outro fator também botou o país em alta nos assuntos internacionais, a sua auto-suficiência em petróleo conseguida há pouquíssimo tempo.

No entanto, as conquistas brasileiras no campo da energia não podem significar um "mundo dourado" de segurança energética para o país. A consecução de segurança em energia, tanto para os combustíveis fósseis, quanto para os renováveis faz parte de um projeto nacional de longo período e não pode perder a dimensão estratégica que o tema exige.

Os últimos quinze anos da história nacional foram marcados pela desagregação do planejamento estratégico necessário a um Estado das dimensões políticas e econômicas como o Brasil. O relativo abandono do planejamento na condição de instrumento de ação governamental em benefício de uma racionalidade do mercado, supostamente mais eficiente, não só foi refutada, mas operou complicações graves na estabilidade brasileira no quesito segurança energética. E, de acordo com a leitura de Ferolla e de Metri ainda é urgente a situação brasileira, como eles observam na prospecção do petróleo e na sorte da Petrobras.

Recebido em 7 de agosto de 2007 Aprovado em 30 de abril de 2008

34 Cf. FRANCO. Afonso Arinos na UnB. Brasília, Universidade de Brasília, 1981. p. 17. 


\section{Referências bibliográficas}

ARON, Raymond. Paz e Guerra entre as Naçôes. 2a edição. Brasília, Universidade de Brasília, 1986. AYOOB, Mohamed. "Inequality and Theorizing in International Relations: The Case of Subaltern Realism”. in International Studies Review. Issue 3, vol. 4. Oxford, 2002.

BATISTA JUNIOR, Paulo Nogueira. Os Mitos da Globalização. Universidade de São Paulo, Instituto de Estudos Avançados, 1997.

BERNANN, Célio. Os Limites dos Aproveitamentos Energéticos para Fins Elétricos: Uma Análise Política da Questão Energética e suas Repercussões Sócio-Ambientais no Brasil. Tese de Doutorado em Engenharia Mecânica. Campinas, Universidade Estadual de Campinas, 1991.

BULL, Hedley. A sociedade anárquica. São Paulo, Brasília; Gráfica Oficial do Estado, Universidade de Brasília, 2002.

CARVALHO, Joaquim de. "Construção e desconstrução do sistema elétrico Brasileiro". in BRANCO, Adriano (org). Política Energética e Crise de Desenvolvimento: A Antevisão de Catullo Branco. São Paulo, Paz e Terra, 2002.

CERVO. Amado Luis. "Um balanço da era Cardoso". in Revista Brasileira de Política Internacional. Nr. 45. Brasília, Universidade de Brasília, 2002.

EVANS et NEWNHAM, Jeffrey (ed.) The Pinguin Dictionary of Internacional Relations. London, Pinguin Books, 1998.

EVANS, Peter. Autonomia e parceria: Estados e transformação industrial. Rio de Janeiro, Universidade Federal do Rio de Janeiro, 2004.

FEROLLA, Sérgio Xavier et METRI, Paulo. Nem todo o Petróleo é nosso. São Paulo, Paz e Terra, 2006.

FERREIRA, Oliveiros, A crise da Politica Externa: autonomia ou subordinação? Rio de Janeiro, Revan, 2001.

FRANCO. Afonso Arinos de Mello. Afonso Arinos na UnB. Coleção Itinerários. Brasília, Universidade de Brasília, 1981.

FIORI, José Luís. "Formação, Expansão e Limites do Poder Global” in FIORI (org). O Poder Americano. Petrópolis, Vozes, 2004.

GOLDENBERG, José et PRADO, Luiz Tadeu. "Reforma e Crise do Setor Elétrico no Período FHC”. in Tempo Social. Revista de Sociologia da USP. Vol. 15, nr. 2. São Paulo, Universidade de São Paulo. 2003.

GOWAN, Peter. A Roleta Global: Uma aposta Faustiniana de Washington para dominar o Mundo. Rio de Janeiro, Record, 2003.

GRAY, John. O falso amanhecer: Equívocos do Capitalismo Global. Rio de Janeiro, Record, 1999.

GRÜN, Roberto. "Reforma do Estado e "Apagão Cognitivo". in Dados: Revista de Ciências Sociais. No. 4, vol. 48. Rio de Janeiro, IUPERJ, 2005. Informação adquirida a 29.11.2007 no sitio http://www.iuperj.br/publicacoes/arquivos-dados/dados200504.pdf

HAGE, José Alexandre Altahyde. Bolivia, Brasil e a Guerra do Gás. Tese de doutorado em Ciência Política. Campinas, Universidade Estadual de Campinas, 2006. 
; “O Brasil na economia internacional”. in Valor Econômico. São Paulo, 04/05/2007.

; "Especialista diz que dependência do gás boliviano não acaba tão cedo". in Jornal do Brasil. (versão online). Informação adquirida em http://jbonline.terra.com.br/extra/2007/11/30/ e30114719.html

HASLAM, Jonathan. A necessidade é a maior virtude: O Pensamento Realista nas Relações Internacionais. São Paulo, Martins Fontes, 2006.

HARVEY, David. O novo Imperialismo. São Paulo, Loyola, 2004.

KELSEN, Hans. Derecho y Paz en las Relaciones Internacionales. México-DF, Fondo de Cultura Econômica, 1986. KEOHANE, Robert. After Hegemony. New Haven, Princeton University Press, 1984.

KRASNER, Stephen. "Structural Causes and Regimes: Regimes as Intervening Variables". in KRASNER (org). Ithaca, Cornell University Press, 1995.

LAFER, Celso. A identidade internacional do Brasil e a Politica Externa Brasileira. São Paulo, Perspectiva, 2001.

OFFE, Claus. Problemas estruturais do Estado capitalista. Rio de Janeiro, Tempo Brasileiro, 1984.

ROSA, Luiz Pinguelli. O apagão: Por que veio? Como sair dele? Rio de Janeiro, Revan, 2001.

SANTOS, Edmilson Moutinho dos. "Petróleo - quadro estratégico-global no início do século XXI". in Política Externa. Nr. 1, vol. 12. São Paulo, Paz e Terra, Universidade de São Paulo, 2003.

SILVA, Golbery do Couto e. Planejamento estratégico. Brasília, Universidade de Brasília, 1981.

SOARES. Guido Fernando. Curso de Direito Internacional Público. Volume 1. São Paulo, Atlas, 2002.

SOLNIK, Alex. A guerra do apagão: A crise de energia elétrica no Brasil. São Paulo, Senac, 2001.

\section{Resumo}

Neste artigo se tem a intenção de analisar algumas questões de política internacional que envolve temas energéticos. Tem-se em conta que as grandes potências dedicam grandes esforços para obter segurança energética por meio de políticas e planejamento estratégico condizente com a situação de conflito e disputa que o assunto provoca. Por conseguinte, o texto procura avaliar se, efetivamente, o Brasil também tem planos e estratégia coerente para dar cabo das questões mais importantes do sistema internacional que toca, inclusive, aos assuntos energéticos.

\section{Abstract}

This paper intents to show some international politics questions in the energetic themes. We have in mind the great powers have strong policy to have energetic security liked to situation from conflict and dispute by energetic goods because they have strategic and plans of actions. Then, we have the same intent to show if, effectively, Brazil has equal strategy of it energetic security. Nowadays, energy issues are part of international system problems. In this fact the theme claims more observations and research to understand some questions from them.

Palavras-chave: Petróleo, Meio Ambiente, Política Energética Brasileira, Biomassa. Words-key: Petroleum, International System, International Politics, Enviroment. Energetic Brazilian Policy. Biomassa. 